\title{
A CONNECTED WORLD: A SYSTEMATIC LITERATURE REVIEW OF THE INTERNET EFFECTS ON SOCIETY
}

\author{
Anthony Romaniello, BentleyUniversity, romanie_anth@bentley.edu \\ Alina Chircu, Bentley University, achircu@bentley.edu
}

\begin{abstract}
Over the past several decades, the Internet has transformed the world and created one large, interconnected, always-on network - the network society. This paper identifies and analyzes the effects of the Internet on many aspects of society through a systematic review of scholarly peer-reviewed papers published in journals archived in two major library databases. The analysis reveals that interest in publishing articles in this area has been increasing over the years, with many ebbs and flows from 1996 until 2017, and that the research area has matured. The research has been published in a variety of journals and has been described by hundreds of subject terms and keywords, showing how expansive this topic is and how far it permeates different facets of society. The majority of studies are produced in the United States and a few other English-speaking countries, although some diversity in the geographic location of the authors' home institutions and location of the research itself exists. Lastly, the analysis highlights specific impacts in several thematic categories. The contribution of this paper is highlighting the many different perspectives regarding the impacts of Internet on society, and thus providing a richer picture of the existing published research.
\end{abstract}

Keywords: Internet, Network Society, Positive and Negative Impacts, Systematic Literature Review

\section{INTRODUCTION}

Over the past several decades, there has been an explosion in the usage of Internet and associated digital technologies worldwide. According to the International Telecommunication Union, a United Nations agency responsible for global information and communication technology oversight, there were over seven hundred million worldwide Internet users at the turn of the $21^{\text {st }}$ century, representing $7 \%$ of the global population. By 2015, however, the Internet had over three billion users, representing $43 \%$ of the world population (Davidson, 2015).

As the Internet becomes more and more ubiquitous every day, the society is quickly becoming a "network society." The network society concept, introduced in the 1990's and made popular by sociologist Manuel Castells, captures a world in which networked information and communications technology such as the Internet has had and continues to have deep-rooted effects on how society functions in many areas (Castells, 2014; Hassan, 2008). One effect described in the literature is changes in communication and socialization behaviors, where, on the one hand, computer games, social media websites, and other online-based activities may lead to less real-world interactions and technology addiction, but, on the other hand, technology enhances and supports socialization and communication. Other effects described by researchers are changes in perceptions of time and space, which become compressed (Hassan, 2008). As a result, on the plus side, the Internet opens up opportunities for quicker communication and better collaboration for individuals and businesses and fast global access to near-infinite information resources from almost any corner of the world. On the minus side, this creates social costs, paid by employees, by encouraging multitasking and an always-on mentality, discouraging work-life balance, and leaving no room to escape people one may not want to interact with, as in the case of cyberbullying.

This paper investigates and classifies the impacts that this Internet-enabled environment has on society by reviewing the academic literature on this topic. The paper is organized as follows. The second section provides a description of the methodology - a systematic process for article identification and selection. The third section describes several analyses of the articles using article meta-data and additional researcher-determined codes, and discusses key insights from each analysis. Lastly, the fourth section summarizes the results, discusses limitations, and presents conclusions and future research directions. 


\section{RESEARCH METHODOLOGY}

This paper employs a systematic literature review methodology, which requires researchers to follow a rigorous and reproducible process in order to develop a comprehensive overview of the literature on a specific topic (Pickering and Byrne, 2014; Tranfield et al., 2003). The systematic literature review has emerged as a valuable management research tool after the development and use of this methodology in the medical field (Tranfield et al., 2003), which also promoted the introduction of the well-known PRISMA standard (Moher et al., 2009). Detailed guides for conducting such reviews now exist (Fink, 2013). The systematic review can help researchers answer descriptive questions about the place and date of publication, the authors of the articles, the geographical focus of the research, and the types of research methods used, as well as thematic questions about research topics and results (Pickering and Byrne, 2014; Tranfield et al., 2003).

Following this methodology, a search for relevant articles was conducted using two major scholarly databases from EBSCO (Academic Search and Business Source), which cover thousands of publications in many disciplines. They were accessed through the authors' university portal. The search was restricted to peer-reviewed journals and to articles with full text available in the database searched. The abstracts of all articles meeting these criteria were searched for the keywords "Internet," "society," and "effects." Note that "Internet" and "society" also cover the ideas that form the basis of the network society, as explained in the introduction, while "network society" was deemed a more restrictive term. The search resulted in 250 articles. The list was further refined by eliminating 26 articles in languages other than English and 34 duplicates, generating 190 articles which were downloaded from the databases and organized in an Excel file for a more detailed eligibility evaluation of titles, abstracts, and other article meta-data. This evaluation resulted in removing 63 more articles from the list for one or more of the following reasons: subject matter unrelated to research topic (as in the case of a medical journal article unrelated to the Internet or network society) or article did not provide sufficient proof for reasoning or findings (as in the case of short - just a few pages long - papers that only stated ideas without any evidence to support them). At the end of this process, the final number of articles retained for review was 127 .

\section{RESULTS}

The first and descriptive part of the analysis focused on insights that could be gained by viewing trends in article metadata, such as place of publication, keywords, subject words, location of the articles, and publication year. The second and thematic part of the analysis focused on coding, classifying and analyzing the articles in several different categories. All of these analyses are detailed below.

As seen in Figure 1, there is a general upward trend in the number of articles published over time. The first paper was published in 1996, but only four articles were published prior to 2000, which makes sense given the Internet was still a very new technology and still not used by the public at large. A total of 88 papers (69\%) were published in the last 10 years, and slightly more than half of those articles (47) were published in the last five years, showing a clear concentration of the research in recent years. Interestingly however, some years with a large number of publications, such as 2009 and 2011, are followed by years with much less publications, such as 2010 and 2011. This pattern is repeated several times, and seems to be less likely due to unusual delays in the review process. Instead, the wave pattern seems to suggest that the researcher interest in the effects of Internet on society have been ebbing and flowing over the years. While the interest in this topic seems to be slowing down in the last few years, it may pick up again as new Internet applications are introduced if the wave pattern holds. 


\section{Issues in Information Systems \\ Volume 19, Issue 3, pp. 110-119, 2018}

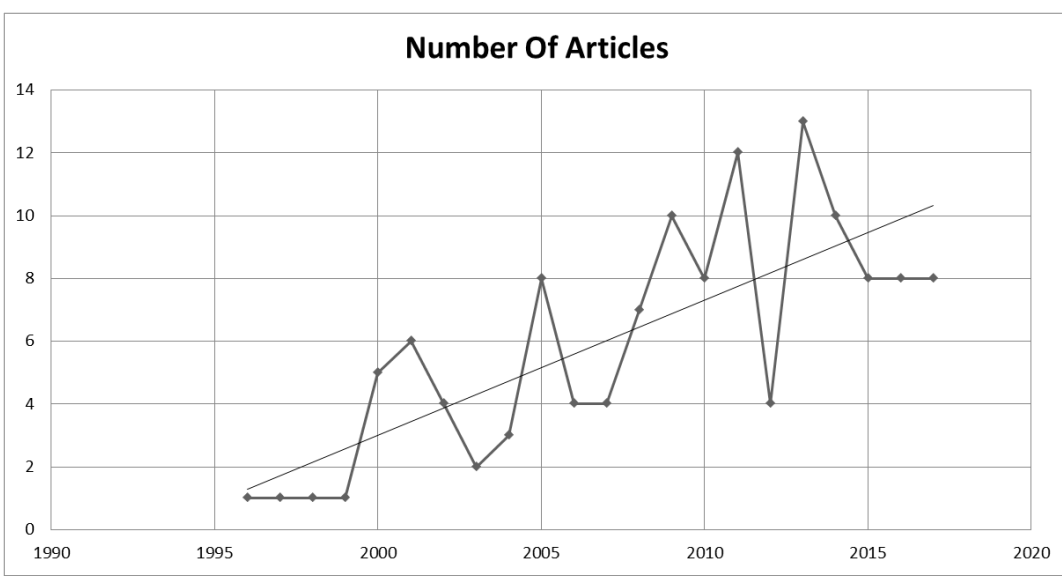

Figure 1. Number of Articles by Publication Year

The next piece of metadata used for the analysis was the frequency of publication in the same journal. Papers were published in 109 unique academic journals, and the vast majority of those journals - 94 - only published one paper on the topic investigated in this research. As seen in Table 1, 15 journals published two or more articles, and the journal at the top of the list, Information Society, only published four articles. The journals come from different disciplines, such as sociology, communication, computer science, information systems, engineering, science and medicine. The analysis of additional metadata recorded in the library databases for each article reveals hundreds of unique subject terms and keywords, suggesting many different facets of the network society and many different conceptual approaches, such as digital divide and social capital, for studying them. These results suggest that the effects of the Internet on society have been studied from multiple perspectives and by different disciplines, but that no major journal outlet for this topic exists.

Table 1. Number of Articles by Journal

\begin{tabular}{|l|l|}
\hline \multicolumn{1}{|c|}{ Journal Name } & Number of Articles \\
\hline Information Society & 4 \\
\hline Trials & 3 \\
\hline International Communication Gazette & 3 \\
\hline Communications of the ACM & 2 \\
\hline PLoS ONE & 2 \\
\hline Children \& Youth Services Review & 2 \\
\hline Engineering Economics & 2 \\
\hline Computers \& Education & 2 \\
\hline International Review of Law, Computers \& Technology & 2 \\
\hline Knowledge, Technology \& Policy & 2 \\
\hline Economics \& Management & 2 \\
\hline Journalism Studies & 2 \\
\hline European Journal of Communication & 2 \\
\hline Journal of Information Technology \& Politics & 2 \\
\hline New Media \& Society & 2 \\
\hline Other journals & 94 (1 article each) \\
\hline
\end{tabular}

When looking at the geographic location of the authors' home institutions, the variety remains but is less pronounced, with researchers from over 30 countries represented and with 14 papers co-authored by researchers from several different countries. The biggest contributor was the United States, which accounts for nearly a fourth of all the articles in this study, followed by multiple-nations research teams, which published about $12 \%$ of articles, and by the United Kingdom, Australia, and Canada, which accounted for $9 \%, 8 \%$, and 5\% of articles respectively. The remaining countries each contributed less than 3\%, or four or fewer articles. It is not surprising to find that most of the largest contributors are English-speaking nations, as the library databases searched are focused primarily on 
English-language journals. However, these English-language journals are now standard in many disciplines and countries, so the lower numbers of authors from non-English-speaking countries may suggest barriers to publication for non-English speakers. In addition, the top countries also tend to have high levels of Internet adoption, making research on Internet's effects on society easier for researchers residing in those countries. It is possible that the effects of the Internet in other countries are slower to emerge, either due to slower adoption or due to different cultural and societal norms. While the cause may not be completely understood, there is clearly a deficit in the amount of research produced outside of the United States and a few other English-speaking countries.

To complement the metadata analyses, additional coding of the papers was done in order to better group together the articles. Three author-determined classifications were manually added to each article. The first classification identified what type of research was being conducted within each article. The categories were Case Study, Survey, and Theoretical, as well as Other (which was used to classify articles that did not have a clear research methodology and were unsuitable for further analysis). The majority of articles were either theoretical papers (56) or surveys (48), with only a small number of case studies (12) and the remaining articles classified as other. The limited number of case studies and the relatively larger number of theoretical papers and surveys suggests that the topic is mature.

The second classification was used to identify where the research within each article was taking place (as opposed to the earlier geographical analysis based on the authors' affiliation). The largest groups for location of research were unspecified (35 articles), international (19 articles), and the United States (16 articles). Articles were coded as unspecified if the article never mentioned a nation as the source of their ideas and findings. These articles seemed to speak about the universal impact that the Internet has on society, rather than focusing on the effects in a particular country. Articles were coded as international if they focused on multi-country regions, such as Asia, the EU, or groups of specific countries. Among the articles that were written with a single nation point-of-view, the United States was the most used location for conducting the research. This is not surprising given the history and level of Internet adoption in the country and the number of US-based researchers (who may find it easier to conduct studies in the same country).

The third manual classification was based on the main subject area of the articles. After reviewing each of the articles, 12 categories of Internet impacts on society were derived: Healthcare, Government, Digital Divide, Media (including both traditional and Internet-based mass communication but excluding social media), Privacy, Social Media, Business, Cognitive Functions, Culture Shifts, Education, Ethics, and Globalization. The variety of categories shows the multi-faceted impacts of Internet on societies worldwide. The areas with the largest number of articles were Government (21), Cognitive Functions (21), Digital Divide (19), Business (11), and Healthcare (10). However, as Figure 2 shows, while these subject areas are more prevalent in published journal papers, there is no dominating topic overall.

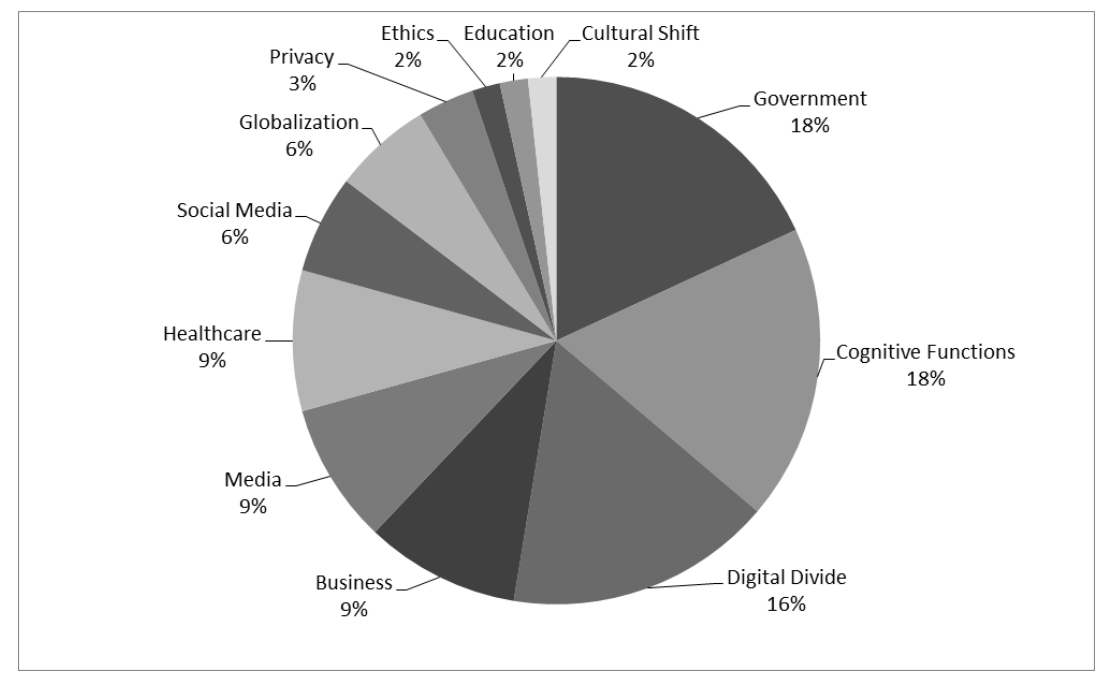

Figure 2. Articles by Main Subject Area 


\section{Issues in Information Systems \\ Volume 19, Issue 3, pp. 110-119, 2018}

Examples of studies conducted in the Government subject area (see Table 2) include research on Internet's impact on improving government efficiency and effectiveness and reforming public management (Asgarkhani, 2013), the evolving public debate regarding government's role in monitoring and even censoring Internet content that is deemed inappropriate (Shallit and Lyons, 1997), the ways that the Internet can shape government elections in highly networked societies like South Korea (Lee, 2009), the difference between using the Internet and traditional media sources for political discourse (Rowe et al., 2006), and the effects of Internet on availability of political information and amount of political engagement (Bimber, 2001), among others.

Table 2. Select Government Articles

\begin{tabular}{|c|l|}
\hline Citation & \multicolumn{1}{c|}{ Main Ideas } \\
\hline $\begin{array}{c}\text { (Shallit and Lyons, } \\
\text { 1997) }\end{array}$ & $\begin{array}{l}\text { As the Internet continues to grow, many people are concerned about what content is } \\
\text { allowable. Governments are questioning the possibility of banning topics that are deemed } \\
\text { harmful to the public. Both sides of the argument have many supporters. }\end{array}$ \\
\hline (Asgarkhani, 2013) & $\begin{array}{l}\text { The Internet has been an effective tool for business and private enterprise in terms of } \\
\text { efficiency. This paper examines its effects on governmental management, and finds that it } \\
\text { holds enormous value for public management if it is properly utilized. }\end{array}$ \\
\hline (Lee, 2009) & $\begin{array}{l}\text { Korea is a highly networked society and many researchers see it as a good testing zone for } \\
\text { the implications of the Internet on governmental elections. In particular, an outsider } \\
\text { candidate was able to win the South Korean presidency in 2002 due to a consolidation of } \\
\text { young liberal votes through online activities. However, the 2007 election reflected a } \\
\text { changing landscape, with more conservatives being online. }\end{array}$ \\
\hline (Rowe et al., 2006) & $\begin{array}{l}\text { Many people tout the benefits of online political discourse, but there is little empirical } \\
\text { evidence to show that the online environment yields better results than traditional media. } \\
\text { However, the Internet is slightly better in attracting an even gender distribution. }\end{array}$ \\
\hline (Bimber, 2001) & $\begin{array}{l}\text { As the Internet has developed and become more pervasive in society, many people have } \\
\text { speculated on the effects it will have on our political systems. This paper finds that while } \\
\text { the Internet lowers the cost and increases the availability of political information, there is } \\
\text { little evidence that the Internet generates more political engagement. }\end{array}$ \\
\hline
\end{tabular}

Articles within the Cognitive Function subject area (see Table 3 for examples) focus on a wide range of issues related to individual cognitive state and development, with both positive and negative impacts. For example, while many popular media sources claim that Internet usage is causing issues with the development of adolescent brains, empirical evidence supports the idea that the Internet creates no harm to a child's cognitive development (Mills, 2014). The Internet can support adjustment when it is used to find social activities or networks within the new setting (Lee et al., 2011). However, as the Internet is providing youngsters with easy access to very violent and gory content (Fedorov, 2005), they become more violent (Ukoha, 2013). In addition, accessing the Internet through devices such as smartphones can create dependence and addiction, especially when the usage is frequent and involves information seeking, entertainment, or gaming (Bae, 2017). And using the Internet to stay in touch with faraway friends and family may decrease social adjustment of young adults to a new environment (Lee et al., 2011).

The Digital Divide category (see Table 4 for examples) includes articles focused on the gap among members of society based on their different access and understanding of Internet and related technologies. Some studies find that many students are being unfairly disadvantaged because their school districts do not have the funding necessary to give easy access to computers and the Internet (Morse, 2004). Having Internet access makes individuals more likely to participate in their communities (Dutta-Bergman, 2005). But certain groups, such as women and elderly people, are very often underrepresented in the world of digital technology (Elnaggar, 2008; Silva et al., 2017). In some nations, including many Arab countries, women lack proper Internet access, especially in comparison to men, due to family pressure, stereotyping, and cultural norms (Elnaggar, 2008). And the gender divide in Internet access seems to hold in many other countries, disadvantaging women, when controlling for other variables (Drabowicz, 2014). 
Table 3. Select Cognitive Function Articles

\begin{tabular}{|c|l|}
\hline Citation & \multicolumn{1}{c|}{ Main Ideas } \\
\hline (Mills, 2014) & $\begin{array}{l}\text { Many people are concerned over the effects of the Internet on the development of } \\
\text { children's brains. While young brains are in their true formative years, many worry that } \\
\text { Internet activities could alter brain structure. This paper concludes that no visible } \\
\text { changes have been noticed. }\end{array}$ \\
\hline (Bae, 2017) & $\begin{array}{l}\text { Smartphones in Asia are increasingly becoming the most used way by which people } \\
\text { and in particular young students gain access to the Internet. This study seeks to find } \\
\text { what factors are correlated with a dependence on smartphones. }\end{array}$ \\
\hline (Ukoha, 2013) & $\begin{array}{l}\text { Today, people and in particular children have more access to entertainment than ever } \\
\text { before. Much of this entertainment is very violent. This study, conducted in Nigeria, } \\
\text { suggests that violent content and in particular violent video games are causing children } \\
\text { and young adults to be more violent, and thus such content should be monitored. }\end{array}$ \\
\hline (Fedorov, 2005) & $\begin{array}{l}\text { Many years ago children in Russia were lucky to have access to basic cassette videos. } \\
\text { Today, regardless of economic level, they have access to advanced interactive } \\
\text { videogames. This paper seeks to find what these games are showing young children and } \\
\text { the ages by which they are consuming this content. }\end{array}$ \\
\hline Lee et al., 2011) & $\begin{array}{l}\text { This article examines the effects of the Internet on the social adjustment of foreign } \\
\text { exchange students in Korea. The authors finds that the Internet can cause either an } \\
\text { increase or a decrease in social adjustment depending on the usage purpose. }\end{array}$ \\
\hline
\end{tabular}

Table 4. Select Digital Divide Articles

\begin{tabular}{|c|l|}
\hline Citation & \multicolumn{1}{c|}{ Main Ideas } \\
\hline (Elnaggar, 2008) & $\begin{array}{l}\text { Throughout the world, technology is allowing women to gain a better knowledge } \\
\text { foothold in the modern era. However, these advantages are not being realized in many } \\
\text { Arab nations, where many women lack proper access, especially in comparison to men. } \\
\text { Many factors contribute to this lack of access and representation in the technology } \\
\text { sphere, including family pressure, stereotyping, and cultural norms. }\end{array}$ \\
\hline $\begin{array}{c}\text { (Dutta-Bergman, } \\
\text { 2005) }\end{array}$ & $\begin{array}{l}\text { In the United States, the Internet has created a social gap between those who have } \\
\text { access and those who do not. This paper finds that having Internet access makes } \\
\text { individuals more likely to participate in their communities. }\end{array}$ \\
\hline (Silva et al., 2017) & $\begin{array}{l}\text { Since the Internet has become such an important part of modern society, it is important } \\
\text { to understand the inequalities that it creates, especially related to the elderly, who have } \\
\text { low Internet adoption rates. Factors associated with Internet usage among those who are } \\
\text { above age fifty include wealth, education, and country of residence. }\end{array}$ \\
\hline (Morse, 2004) & $\begin{array}{l}\text { Brown vs. Board of Education established that, in the U.S., all students have a right to } \\
\text { the same education. However, the Internet has created a form of segregation. Students } \\
\text { from wealthy areas are able to access technology and use it to develop themselves fully, } \\
\text { while students from less wealthy areas have no access or have only low-quality access. }\end{array}$ \\
\hline (Drabowicz, 2014) & $\begin{array}{l}\text { This paper studies Internet access in 39 different countries by gender. The results } \\
\text { indicate that men do seem to have more Internet access than women when controlling } \\
\text { for other variables. }\end{array}$ \\
\hline
\end{tabular}

In the realm of business, researchers present many different viewpoints of the potential effects of Internet on society (see Table 5 for a sample). Information and communication technology has opened up the world of business to more efficient ways of operating, and can be further used to create better ways of running businesses (Laitner, and Ehrhardt-Martinez, 2009). However, the Internet has also opened up a whole new avenue in which con-men and other white-collar criminals can take advantage of people (Langenderfer and Shimp, 2001). Risks are inherent in many of the new ways of doing business. One example is crowdfunding, which allows companies that would traditional not have access to large amounts of capital to raise funds and test the marketability of new ideas, but also creates risks due to weak protection both legally and financially and from fraudsters on crowdfunding sites (Leela, 2016; Valanciene and Jegeleviciute, 2013). Thus, the business-focused articles show both the positive effects and potential downsides to the wide-scale adoption of the Internet for economic activities. 


\begin{tabular}{|c|l|}
\hline \multicolumn{2}{|c|}{ Table 5. Select Business Articles } \\
\hline $\begin{array}{c}\text { Citation } \\
\begin{array}{c}\text { (Laitner, and } \\
\text { Ehrhardt-Martinez, } \\
\text { 2009) }\end{array}\end{array}$ & $\begin{array}{l}\text { Information and communication technology has been helping grow the economy and } \\
\text { make the world more energy efficient, but these technologies still have much potential } \\
\text { yet to be discovered. }\end{array}$ \\
\hline $\begin{array}{c}\text { (Langenderfer and } \\
\text { Shimp, 2001) }\end{array}$ & $\begin{array}{l}\text { The growth of the Internet has provided scammers a more effective and large network } \\
\text { of people to hustle. Scammers in particular seem to focus on Internet users that have the } \\
\text { most vulnerability of being trustworthy, namely elderly people. While solutions from } \\
\text { law enforcement or the academia are lacking, swindlers will continue to prey on these } \\
\text { vulnerable individuals. }\end{array}$ \\
\hline $\begin{array}{c}\text { (Leela, 2016) } \\
\text { Crowdfunding has become a valuable way to start new ventures, but many people lack } \\
\text { the understanding of risks associated with it. Individuals who give money to crowdfund } \\
\text { often lack the information and knowledge around potential risks of crowdfunding } \\
\text { projects and platforms. }\end{array}$ \\
\hline $\begin{array}{l}\text { Jegeleviciute, 2013) } \\
\text { not have access to large amounts of capital to find funding and test new ideas. } \\
\text { However, crowdfunding comes with risks, including weaker protection both legally and } \\
\text { from fraudsters on crowdfunding sites. }\end{array}$ \\
\hline
\end{tabular}

Articles in the Media subject area highlight both positive and negative Internet impacts as well (see Table 6 for examples). On the positive side, the Internet has created a new range of journalism focused on much more than edited content (Deuze, 2003), and is opening up scientific journals to a larger public (Secko, 2009), among others. And contrary to predictions, digital media does not destroy social capital; instead, it might even have a slight positive effect (Gerber et al., 2016). However, search engine algorithms can be biased towards certain media outlets, restricting the news people can receive without using multiple search engines (Mowshowitz and Kawaguchi, 2002). Another negative effect is due to the new social complexity created by digital media (Qvortrup, 2006).

Table 6. Select Media Articles

\begin{tabular}{|c|l|}
\hline Citation & \multicolumn{1}{c|}{ Main Ideas } \\
\hline (Deuze, 2003) & $\begin{array}{l}\text { The Internet is redefining journalism activities though key online publishing } \\
\text { characteristics - hypertextuality, interactivity, and multimediality. }\end{array}$ \\
\hline $\begin{array}{c}\text { (Mowshowitz and } \\
\text { Kawaguchi, 2002) }\end{array}$ & $\begin{array}{l}\text { This article shows that different search engines tend to have bias towards certain sites. } \\
\text { The only real way to counteract this bias is by using multiple search engines. }\end{array}$ \\
\hline (Qvortrup, 2006) & $\begin{array}{l}\text { Media is going through a paradigm shift from old media to digital media. This article } \\
\text { attempts to discuss digital media using complexity theory. }\end{array}$ \\
\hline (Gerber et al., 2016) & $\begin{array}{l}\text { Many people argue that new technologies have a destructive effect on people's social } \\
\text { capital, but the evidence indicates a very small, if any, positive impact. }\end{array}$ \\
\hline (Secko, 2009) & $\begin{array}{l}\text { The Internet is changing the way that scientific articles are written, published and } \\
\text { updated, and can allow open access to the larger public. }\end{array}$ \\
\hline
\end{tabular}

Last, but not least, the Healthcare subject area contains many articles focused on the impacts, mostly positive, of the Internet (see Table 7 for examples). For example, having access to high-quality information helps provide assurance to people going into major surgery, and helps reduce pre-surgery anxiety (Tulgar et al., 2017). This idea is reinforced in other articles arguing that having access to information allows patients to gain better control of their health and body (Forger, 2001). In addition, technology has helped many healthcare organizations improved quality of care and internal operations (Lin and Umoh, 2002). However, on the negative effects side, while many healthcare websites provide information about treatment and other important care aspects, they can misinform patients by neglecting to mention the life-threatening nature of certain diseases such as advanced cancer (Chik and Thomas, 2015). And the evidence regarding how the abundance of healthcare information affects patient decision-making, attitudes, knowledge, satisfaction, and health outcomes and utilization is lacking (Bessel et al., 2002). 
Table 7. Select Healthcare Articles

\begin{tabular}{|c|l|}
\hline Citation & \multicolumn{1}{c|}{ Main Ideas } \\
\hline (Tulgar et al., 2017) & $\begin{array}{l}\text { Many people are often stressed before major surgery. Gaining more high quality } \\
\text { information before the procedure helps to reduce anxiety and information desire. }\end{array}$ \\
\hline (Forger, 2001) & $\begin{array}{l}\text { The environment has great impacts on the people's health. The Internet provides the } \\
\text { ability for the average person to find learning resources and educate themselves about } \\
\text { these impacts, and empowers people to take control of their health. }\end{array}$ \\
\hline $\begin{array}{c}\text { (Chik and Thomas, } \\
\text { 2015) }\end{array}$ & $\begin{array}{l}\text { This article investigates how effective medical websites are at giving patients } \\
\text { information about certain serious diseases, and how having this information shapes the } \\
\text { experience patients have with their doctors. The majority of the websites studied neglect } \\
\text { to mention the life-threatening aspects of the diseases. }\end{array}$ \\
\hline (Lin and Umoh, & $\begin{array}{l}\text { The explosion of the Internet has benefited the healthcare industry by lowering costs, } \\
\text { reducing errors and lawsuits, better managing supply, and securing patient information. }\end{array}$ \\
\hline (Bessel et al., 2002) & $\begin{array}{l}\text { The Internet gives the average patients access to vast arrays of information that were } \\
\text { previously unknown to them. This could impact patient decision-making, attitudes, } \\
\text { knowledge, satisfaction and health outcomes and utilization. This article finds a lack of } \\
\text { evidence regarding these impacts. }\end{array}$ \\
\hline
\end{tabular}

\section{CONCLUSIONS AND FUTURE RESEARCH DIRECTIONS}

This paper identifies and analyzes the effects of Internet on society through a systematic review of scholarly peerreviewed papers published in journals archived in major library databases. The analysis reveals that interest in publishing articles about the effects of Internet on society has been increasing over the past two and half decades, with many ebbs and flows, and that the research area has matured. The research has been published in a variety of journals (over 100), and has been described by hundreds of subject terms and keywords, showing how expansive this topic is and how far it permeates different facets of society. The majority of studies are produced in the United States and a few other English-speaking countries, although some diversity in the geographic location of the authors' home institutions and location of the research itself exists. Lastly, the analysis highlights that specific impacts occur in 12 broad categories, with the majority of the effects - positive and negative - occurring in the areas of government, individual cognitive state and development, digital divide, business, and healthcare.

It is also important to note the limitations of this research. First, while the databases used for identifying relevant articles cover thousands of full-text journals in a variety of science, technology and business disciplines, it is possible that some articles were left out by not searching in additional databases. Expanding the set of databases is recommended in future research projects as long as time, resources, and analysis details tradeoffs can be managed. Second, the results are specific to the particular choice of search keywords, which were selected to capture the broadest set of articles regarding the effects of Internet on society. Future research can explore different or more specific search keywords and phrases. Finally, the search process excluded non-full-text articles from the search results, which can create selection bias. However, the process was rigorous and clear, and could be replicated in future research if the full text of such articles can be found so they can be added to the current list.

Many people tend to argue one way or another whether the Internet is providing benefits or harms to society. However, this systematic review of the literature indicates that things are not so black and white. Some articles find that the Internet has no significant effect, positive or negative, on people. Other articles point out that the Internet has created many benefits, such as increased business efficiency, better communications, or easier social adjustment. And yet a third group of articles argue that the Internet has a truly negative impact on society, creating more opportunities for scams or promoting violent content to children. Overall, there seems to be no consensus on a clear direction for the huge range of effects caused by the Internet on society. This paper differs from many existing network society papers, which chose to focus on only one particular area of society affected by the Internet. Thus, the contributions of this paper are combining different perspectives through a comprehensive literature review, providing a fuller, richer picture of the published research so far, and serving as a building block for future studies. Ultimately, we hope that this paper will inspire other researchers to design ways to reduce the negative impacts of the Internet on society without diminishing its positive effects. 


\section{REFERENCES}

Asgarkhani, M. (2005). Digital government and its effectiveness in public management reform. Public Management Review, 7(3), 465-487.

Bae, S. (2017). The relationship between the type of smartphone use and smartphone dependence of Korean adolescents: National survey study. Children \& Youth Services Review, 81(10), 207-211.

Bessell, T. L., McDonald, S., Silagy, C. A., Anderson,J. N., Hiller, J. E., \& Sansom, L. N. (2002). Do Internet interventions for consumers cause more harm than good? A systematic review. Health Expectations, 5(1), 28-37.

Bimber, B. (2001). Information and political engagement in America: The search for effects of information technology. Political Research Quarterly, 54(1), 53-67.

Castells, M. (2014). The impact of the Internet on society: A global perspective. Change: 19 Key Essays on How the Internet Is Changing Our Lives, BBVA Open Mind, 9-24. Available: https://www.bbvaopenmind.com/wpcontent/uploads/2014/03/BBVA-OpenMind-Internet-Manuel-Castells-The-Impact-of-the-Internet-onSociety-A-Global-Perspective.pdf.

Chik, I. \& Smith, T. J. (2015). Obtaining helpful information from the Internet about prognosis in advanced cancer. Journal of Oncology Practice, 11(4), 327-331.

Davidson, J. (2015). Here's How Many Internet Users There Are. Time. Available: http://time.com/money/3896219/Internet-users-worldwide/.

Deuze, M. (2003). The web and its journalisms: Considering the consequences of different types of newsmedia online. New Media \& Society, 5(2), 203-230.

Drabowicz, T. (2014). Gender and digital usage inequality among adolescents: A comparative study of 39 countries. Computers \& Education, 74(05), 98-111.

Dutta-Bergman, M. (2005). Access to the Internet in the context of community participation and community satisfaction. New Media \& Society, 7(1), 89-109.

Elnaggar, A. (2008). Towards gender equal access to ICT. Information Technology for Development, 14(4), 280293.

Lee, E., Lee, Lu, \& Jang, J. (2011). Internet for the internationals: Effects of Internet use motivations on international students' college adjustment. CyberPsychology, Behavior \& Social Networking, 14(7), 433437.

Lin, B., \& Umoh, D. (2002). E-healthcare: A vehicle of change. American Business Review, 20(2), 27-32.

Fedorov, A. V. (2005). School students and computer games with screen violence. Russian Education \& Society, 47(11), 88-96.

Fink, A. (2013). Conducting research literature reviews: from the Internet to paper. Sage Publications.

Forger, G. (2001). Environmental health: Finding consumer resources on the Internet. Health Care on the Internet, $5(1), 31-37$.

Geber, S., Scherer, H., \& Hefner, D. (2016). Social capital in media societies: The impact of media use and media structures on social capital. International Communication Gazette, 78(6), 493-513. 
Hassan, R. (2008). The information society: Cyber dreams and digital nightmares. Polity.

Laitner, J. A., \& Ehrhardt-Martinez, K. (2009). Information and communication technologies: The power of productivity (part II). Environmental Quality Management, 18(3), 19-35.

Langenderfer, J., \& Shimp, T. A. (2001). Consumer vulnerability to scams, swindles, and fraud: A new theory of visceral influences on persuasion. Psychology \& Marketing, 18(7), 763-783.

Lee, Y. (2009). Internet election 2.0? Culture, institutions, and technology in the Korean presidential elections of 2002 and 2007. Journal of Information Technology \& Politics, 6(3), 312-325.

Leela, V. (2016). Crowdfunding: A study of risk factors. South Asian Journal of Management, 23(3), 170-192.

Mills, K. L. (2014). Effects of Internet use on the adolescent brain: Despite popular claims, experimental evidence remains scarce. Trends in Cognitive Sciences, 18(8), 385-387.

Morse, T. E. (2004). Ensuring equality of educational opportunity in the digital age. Education \& Urban Society, $36(3), 266-279$

Mowshowitz, A., \& Kawaguchi, A. (2002). Bias on the web. Communications of the ACM, 45(9), 56-60.

Pickering, C.M., \& Byrne, J. (2014). The benefits of publishing systematic quantitative literature reviews for PhD candidates and other early career researchers. Higher Education Research and Development, 33, 534-548.

Qvortrup, L. (2006). Understanding new digital media. European Journal of Communication, 21(3), 345-356.

Rowe, G., Poortinga, W., \& Pidgeon, N. (2006). A comparison of responses to Internet and postal surveys in a public engagement context. Science Communication, 27(3), 352-375.

Secko, D. M. (2009). The unfinished science story: Reflections on journalist-audience interactions in the online environment. Journal of Media Practice, 10(2), 259-266.

Shallit, J., \& Lyons, H. (1997). Social issues of networking in Canada's information society. Information Society, 13(2), 147-151.

Silva, P., Matos, A. D., \& Martinez-Pecino, A. (2017). E-inclusion: Beyond individual socio-demographic characteristics. Plos One, 12(9), 1-10.

Tranfield, D., Denyer, D., \& Smart, P. (2003). Towards a methodology for developing evidence-informed management knowledge by means of systematic review. British journal of management, 14(3), 207-222.

Tulgar, S., Boga, I., Piroglu, M. D., Ates, N. G., Bombaci, E., Can, T., Selvi, O., Tas, Z., \& Kose, H. K. (2017). Preoperative anxiety before spinal anesthesia: Does Internet-based visual Information/Multimedia research decrease anxiety and information desire? A prospective multicentered study. Anesthesia: Essays \& Researches, 11(2), 390-396.

Ukoha, E. (2013). Media violence and violent behaviour of Nigerian youths: Intervention strategies. Ife Psychologia, $21,230-237$.

Valanciene, L., \& Jegeleviciute, S. (2013). Valuation of crowdfunding: Benefits and drawbacks. Economics \& Management, 18(1), 39-48. 